\title{
10th Anniversary of Clinical Endoscopy
}

\author{
Eun Young Kim \\ Department of Internal Medicine, Daegu Catholic University School of Medicine, Daegu, Korea
}

This issue of Clinical Endoscopy (Clin Endosc, CE) celebrates 10 years of its successful publication since its first launch in September 2011. The Korean Society of Gastrointestinal Endoscopy (KSGE) was established on August 14, 1976. KSGE published the first issue of its official journal titled "The Korean Journal of Gastrointestinal Endoscopy" in Korean in October 1981. Since then, "The Korean Journal of Gastrointestinal Endoscopy" has served as a valuable source of knowledge in the field of gastrointestinal (GI) endoscopy for Korean doctors. After 30 years of dedication, KSGE has decided to transform the journal to a globally contributing knowledge hub and has launched CE published in English in September 2011 (Fig 1). This month, September 2021, marks the $10^{\text {th }}$ anniversary of the founding of CE.

$\mathrm{CE}$ has performed its role very well as a vehicle for sharing knowledge during the last 10 years and has now become one of the leading journals in the field of GI endoscopy. It is indexed in many recognized databases such as KoreaMed (September 22, 2011), PubMed Central (PMC)/PubMed (June 28, 2012), Scopus (November 11, 2013), EBSCO (June 29, 2015), Emerging Sources Citation Index (ESCI) (June 6, 2016), DOAJ (April 28, 2018), and Embase (January 1, 2019). About 1,200 papers related to GI endoscopy were published in CE from September 2011 to July 2021, and there were submissions from various countries all over the world. Last year,

Received: August 18, 2021 Revised: August 23, 2021

Accepted: August 23, 2021

Correspondence: Eun Young Kim

Division of Gastroenterology, Department of Internal Medicine, Daegu Catholic University School of Medicine, 33 Duryugongwon-ro 17-gil, Nam-gu, Daegu 42472, Korea

Tel: +82-53-650-4092, Fax: +82-53-621-4487, E-mail: kimey@cu.ac.kr ORCID: https://orcid.org/0000-0003-3965-9964

(c) This is an Open Access article distributed under the terms of the Creative Commons Attribution Non-Commercial License (http://creativecommons.org/ licenses/by-nc/3.0) which permits unrestricted non-commercial use, distribution, and reproduction in any medium, provided the original work is properly cited. authors from more than 43 countries submitted their papers to $\mathrm{CE}$, and there were about 25,000 electronic downloads from the journal.

To celebrate this wonderful occasion, three special articles were prepared in this issue, including this editorial. The next one is a review article that summarizes remarkable articles published in CE selected by each deputy editor from one's subspecialty. The last article is an original article about bibliometric analysis of articles published from 2015 to May 2021 in CE based on the Web of Science Core Collection. Readers may find the history and current position of CE with these special papers and participate in the celebration of its $10^{\text {th }}$ founding anniversary.

For the last ten years, William Y. Chey, who has been the Editor-in-Chief of CE since its inauguration, and editors, including Jeong Seop Moon and Ki Baik Hahm, former directors of the Editorial Committee of KSGE, have faithfully worked for CE. There has also been a devotion of 39 editorial board members from 22 countries for CE to publish many precious articles helping gastroenterologists to share and accumulate their knowledge in the field of experimental, diagnostic, and therapeutic GI endoscopy.

In 2021, the Vietnam Association of Gastroenterology (VNAGE)/Vietnam Federation for Digestive Endoscopy (VFDE) and Thai Association for Gastrointestinal Endoscopy (TAGE) designated CE as the societies' official journal. Previously, the International Digestive Endoscopy Network (IDEN), which was established in 2019 to promote and share the development of advanced digestive endoscopy research, also nominated CE as its official journal. These kinds of international cooperation would enhance the opportunities for researchers to publish their latest work, thereby stimulating scientific progress in the area of GI endoscopy.

As the current director of the publication committee of KSGE, I would like to express my sincere appreciation for the contributions of authors, reviewers, editorial board members, 

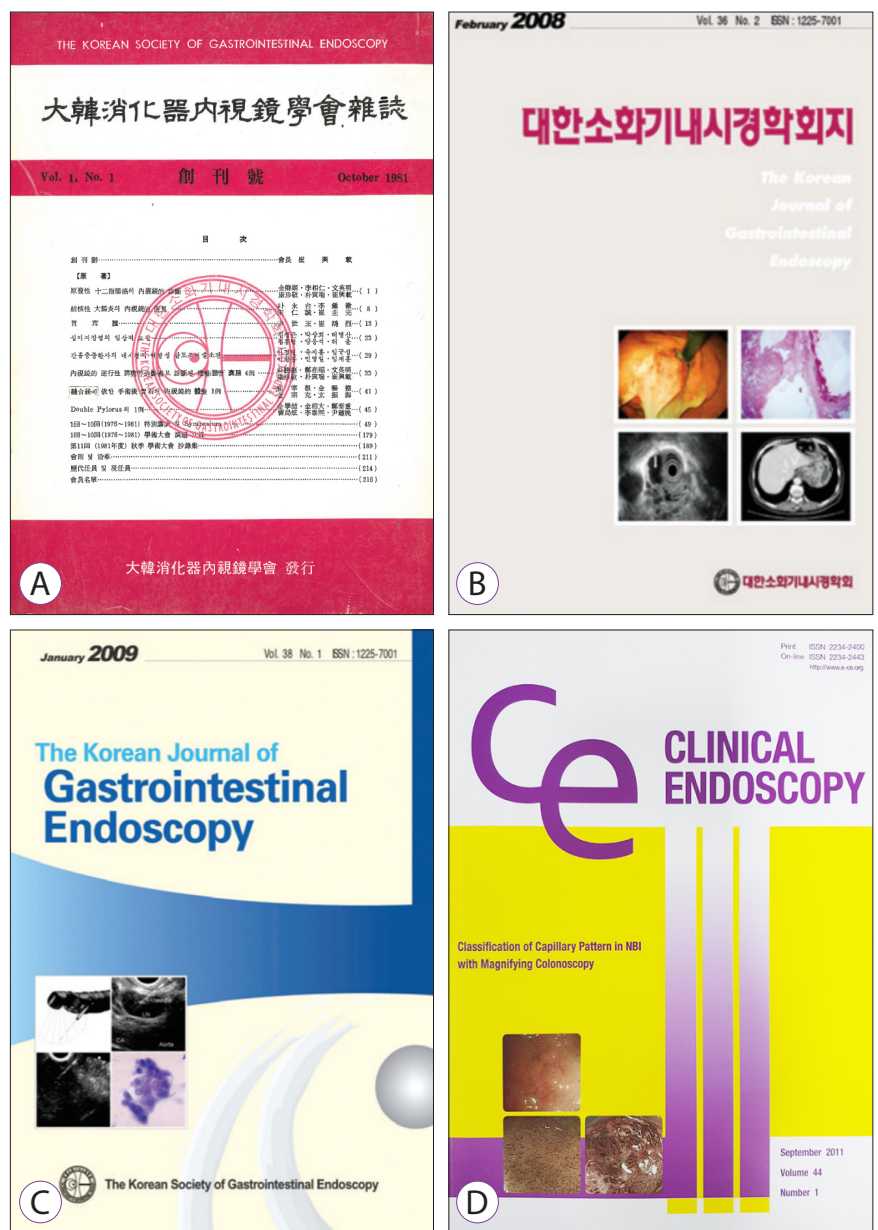

Fig. 1. Photos showing the changes in the journal cover design. (A) The journal cover of the first issue of "The Korean Journal of Gastrointestinal Endoscopy". (B) The second design of the journal cover written in Korean. (C) The third design of the journal cover written in English. (D) The journal cover of the first issue of the Clinical Endoscopy.

and editors of the $\mathrm{CE}$ journal in the last 10 years. This achievement would only be the beginning of the great success of this journal in accomplishing and promoting the exchange of upto-date scientific information clinically and experimentally in the field of GI endoscopy. Last but not least, I would like to extend my deepest thanks to all the devoted readers who had supported CE during the 10 years process of growth.

\section{Conflicts of Interest}

Eun Young Kim is currently serving as a deputy editor in Clinical Endoscopy; however, she had not involved in the peer reviewer selection, evaluation, or decision process of this article. The author has no potential conflicts of interest.

\section{Funding}

None.

ORCID

Eun Young Kim:

https://orcid.org/0000-0003-3965-9964 